\title{
Editor's Introduction: Pedagogy, Ethics and The Sociological Imagination
}

\author{
Lawrence T. Nichols ${ }^{1}$
}

Published online: 7 August 2018

C) Springer Science+Business Media, LLC, part of Springer Nature 2018

This issue features six papers that range widely, from the pedagogical to the pragmatic, and from the micro realm of the classroom to the macro arena of globalizing modernity.

Matthias Revers and Casey Brienza begin with a critical examination of efforts to create a sociology of media, a specialized field they believe is vital in the context of recent transformations of communication practices in technologically advanced societies. In their view, an opportunity to establish media sociology appeared in the 1970s and 1980s, but sociologists did not take advantage of it due to three major factors: ideas then dominant in the field, the institutional-disciplinary history and intra-disciplinary politics. But the challenge remains.

Roberta Garner and Blackhawk Hancock next offer a thoughtful proposal for the pedagogical reintegration of theories, methods and historical analysis. These authors are concerned about the harmful effects of cleavages in academic departments of sociology between "theory and method" or "qualitative and quantitative" approaches or "historical and non-historical" treatments, all of which are detrimental to the development of students. They retain an optimism that, where collective motivation is present, such artificial dichotomies can be overcome.

Milton Friesen's paper presents a methodological proposal, specifically a new instrument to measure social capital that was developed on the basis of the General Social Survey database in Canada. The instrument is designed in particular to gauge the extent of interpersonal trust in urban settings, at the level of census tracts and neighborhoods. The author believes this Social Capital GSS will be especially useful for researchers because of its affordability and efficiency.

Pavel Sorokin's paper provides a macro perspective on ethical challenges facing sociology in the context of global modernity. After critiquing currently dominant discourses, the author develops an alternative based on ideas from Pitirim Sorokin, John Meyer and Volker Schmidt. The emphasis here is on "solidarity-oriented and ethically contextualized sociological communication" that recognizes a world of

Lawrence T. Nichols

lnichol2@wvu.edu

1 West Virginia University, Morgantown, WV, USA 
diverse ethical systems that are ultimately irreducible to one another or to a hegemonic, European and western-centered set of values.

Amy Best and Roberta Spalter-Roth venture into the arena of policy sociology with a proposal for a "relational network approach." The analysis originates in a concern with the widespread perception that sociology is not especially relevant to policy formation, and that the field's contribution has steadily declined. To counter this view, Best and Spalter-Roth detail exemplars of how sociologists have made a difference in actual ameliorative policies, based on an NSF funded professional workshop. They seek to translate the "lessons" of that workshop into "tools" that "better equip social scientists to bring their research into the public policy realm."

Jensen Sass, finally, responds to Andrew Abbott's recent article in this journal on "varieties of normative inquiry." Sass articulates a view that generally accords with Abbott's, but one that the author considers more feasible because it does not entail "wholesale institutional change." Sass concludes by pointing to the normative sociology of former ASA president James Coleman as a model worthy of emulation.

Readers should find much here that relates to their own lived experiences in the field, beginning perhaps with the sharp divisions described by Garner and Hancock that have often bred conflict within academic departments and the profession more generally. Their discussion brings to mind the work of Robert Merton on reward systems in science, in the sense that such systems by becoming increasingly differentiated over time, have generated the gaps between theory and method or quantitative and qualitative approaches and have rewarded their persistence. From the perspective of building a career in academic sociology, there is practical wisdom - even necessity - in choosing between a focus on theory or methods, and in choosing further whether to specialize in qualitative or quantitative strategies of analysis. On the basis of such decisions - often determined largely during doctoral studies - newcomers enter into differential networks in which they develop professional work products, such as publications and grant applications, while also participating in differential conferences and writing and reviewing for differential journals. Such networks are generally located outside of academic departments, though there are sometimes intradepartmental "working groups" that might promote integration along the lines that Garner and Hancock favor.

But the pressures toward separation and segregation will be difficult to overcome. Colleagues committed to feminist method, for instance, will attend feminist conferences, participate in the gender section of ASA, and submit to Gender and Society or similar feminist journals. They will not attend events such as conferences on "critical theory" that feature foundational writings by men working within a Marxist frame of reference. Others, whose research is quantitative, will attend special workshops on the latest statistical techniques and will submit their work to the "top three" U.S. journals (ASR, AJS, Social Forces) or others that feature multiple regression analysis (e.g., Criminology). Symbolic interactionists will build careers via the Society for the Study of Symbolic Interaction or through participation in the annual Couch-Stone symposium, and submit research to the journal Symbolic Interaction or to Norman Denzin's series, Studies in Symbolic Interaction. Readers can doubtless supply additional examples, perhaps in other national contexts, all of which push the field toward what Jonathan Turner has called "differentiation without integration," that is, the condition that Garner and Hancock wish to overcome. 
Meanwhile the response of Jensen Sass to Andrew Abbott provides support for reconsidering the notion of the sociological imagination that has been a cornerstone of the discipline and can be found in the self-presentations on many departmental websites. Formulated by C. Wright Mills in his influential overview of the field, the concept has been frequently linked to the conflict approach that has arguably been hegemonic now for about half a century. As readers are well aware, the popularity and influence of paradigms waxes and wanes, and there seem now to be symptoms suggesting that the conflict perspective - a valuable corrective to the earlier overemphasis on cooperative relations in society - may be approaching the end of its reign. I have myself advocated the Integral approach developed by Pitirim Sorokin that incorporates both the cooperative and conflict points of view, but this comes up against a widespread tendency in the field to emphasize one or the other basic process.

For many among recent generations of sociology students, as well as professors, the conflict approach has been the only legitimate perspective, an outlook supported in numerous introductory textbooks (as Christian Smith has argued). This pattern is reinforced by another, namely the selection of sociology by those who have personal grievances (often justified) and who wish to use the field as a means of "working for change" or "making a difference." For those desiring to do battle for what they regard as a righteous cause, earlier functionalist formulations may seem false consciousness, if not actually complicity in evil, while the Integral approach may seem bland and overly balanced and not sufficiently angry in the face of obvious injustice. This is especially the case for those who have internalized the message in many sociology courses and departments that fighting inequality is "sociology's brand" or "sociology's mission," a formula that might (from a functionalist standpoint) actually be an adaptive strategy to position sociology within academia while also combatting anomie in the field (i.e., by infusing a sense of high purpose). The argument I have advanced that justice is not the highest value in western culture (that place belongs to love), and that without a connection to other primary values such as compassion and loving-kindness justice easily degenerates into - or becomes a cover story for-vengeance and violence, will probably fail to move those who are angry about exploitation and oppression and human suffering. Such righteous anger, a response easily understood in the present socio-political context in the U.S., will tend to extend the hegemony of the conflict perspective. At the same time, however, the intellectual limitations of the conflict view (e.g., the assumption of the fundamental incompatibility of group interests) and its obsessive negativism will motivate some to seek an alternative, if not Integralism then perhaps "pure sociology" (along the lines of Donald Black's work) or the more eclectic and ecumenical "varieties of sociological imagination" that Abbott advocates. Perhaps this will bring about a new split between conflict and non-conflict (but not functionalist in the earlier sense) factions in the field, and to the emergence of new professional associations, as well as new journals or other publication outlets for the competing perspectives. And this will become a new challenge to the field's already problematic solidarity, though perhaps one that can be successfully met if sufficient good will among colleagues remains. 